Ano 6, Vol. 6 (1), no 1. 2021, janeiro/julho de 2021.

\title{
A figura feminina em Chapeuzinho Vermelho e Chapeuzinho Amarelo
}

Luiz Felipe Verçosa da Silva, UFPE - Universidade Federal de Pernambuco; E-mail: felipevercosa@outlook.com; José Antonio Santos de Oliveira, UFPE - Universidade Federal de Pernambuco; E-mail: jaletras1997@gmail.com

RESUMO - Chapeuzinho Vermelho, texto dos irmãos Grimm publicado em 1857, é um conto de fadas bastante popular da Literatura Infantil mundial. Sua história perpassou fronteiras e contribuiu para o imaginário de muitas gerações de crianças. Já Chapeuzinho Amarelo, escrito por Chico Buarque em 1979, estabelece uma relação significativa de intertextualidade com a primeira versão do conto pueril, enfatizando o medo dos fantasmas na infância. Portanto, o objetivo deste trabalho é perceber como as personagens Chapeuzinho se correlacionam dialogicamente e revelam, através de suas narrativas, as várias faces do inconsciente humano, marcado pelos traumas e por manifestações de um erotismo abstrato. Para a fundamentação teórica, utilizar-se-á as contribuições de Carvalhal (2006), Candido (1996) e Bettelheim (2007).

Palavras-chave: Intertextualidade. Conto de Fadas. Feminino.

ABSTRACT - Little Red Riding Hood, a text by the Grimm brothers published in 1857, is a very popular fairy tale from children's literature worldwide. Its history crossed borders and contributed to the imagination of many generations of children. Chapeuzinho Amarelo, written by Chico Buarque in 1979, establishes a significant intertextual relationship with the first version of the puerile tale, emphasizing the fear of childhood ghosts. Therefore, the objective of this work is to understand how Chapeuzinho characters dialogically correlate and reveal, through their narratives, the various faces of the human unconscious, marked by traumas and manifestations of an abstract eroticism. For the theoretical foundation, the contributions of Carvalhal (2006), Candido (1996) and Bettelheim (2007) will be used.

Keywords: Intertextuality. Fairy Tales. Feminine.

\section{Introdução}

A Literatura Infantil participou da formação histórica da humanidade. Seu poder imagético instiga crianças no descobrimento de mundos inimagináveis, no qual, a leitura fornece percepções, conhecimentos e, sobretudo, o florescimento de reflexões sobre as 
primeiras personagens marcantes da infância. Pois, ao descortinar universos fictícios, o ser pueril consegue imaginar as situações que circundam o enredo dos contos.

Nesse sentido, este trabalho pretende analisar a partir dos norteamentos da Literatura Comparada, a construção da figura feminina nos textos de Chapeuzinho Vermelho e Chapeuzinho Amarelo, observando como a presença do feminino é construída desde o início dos textos infantis, quando os contos eram transmitidos ainda pela oralidade, no século XVIII.

Nessa mesma época Charles Perrault registrou a primeira versão de Chapeuzinho Vermelho, posteriormente, também registrada pelos irmãos Grimm. Os textos se tratam de uma narrativa alegórica, que traz uma menina como protagonista.

De acordo com GOTLIB (2006, p. 29) "O que caracteriza o conto é o seu movimento enquanto uma narrativa através dos tempos". Eis nesta afirmação algo interessante para pensar sobre a história mencionada, uma vez que, de fato, a narrativa da jovem Chapeuzinho Vermelho encontra-se reavivada até os dias atuais, como na versão feita por Chico Buarque de Hollanda, escrita em 1979.

O livro do músico e escritor brasileiro estabelece contato nítido com a obra dos escritores alemães, pois o texto narrado em versos passa a ser intitulado Chapeuzinho Amarelo. Além disso, o texto enfatiza os medos infantis a partir de um olhar feminino, sendo que sua produção é elaborada em diálogo intertextual com o conto de Wilhelm e Jacob Grimm. Entretanto, observa-se na obra de Hollanda uma ruptura brusca na personalidade da menina, que agora, além de enfrentar os medos, até brinca com eles.

Por isso, o objeto deste estudo é pertinente para a compreensão da imagem feminina. Pois nessa literatura direcionada às crianças, emergem personagens femininos singulares, cuja contribuição social mostra-se fecunda, uma vez que esses textos são acompanhados justamente por características ligadas ao contexto de sua escrita. Ou seja, elas evidenciam em suas estruturas narrativas, como eram os comportamentos sociais na época e a maneira pela qual a mulher era vista.

\section{A literatura comparada}


A Literatura comparada (LC) configura-se como uma vertente crítica e analítica de textos literários, que perpassam fronteiras nacionais, levando o comparativista a desenvolver leituras inovadoras sobre o seu corpus de análise. Além de promover relações significativas por meio da intertextualidade ou, decerto, os traços de influência, presentes nas obras literárias.

Ademais, esta linha de pesquisa não corrompe os textos estudados, mas, a partir da LC, podem-se granjear múltiplos sentidos, antes ocultos em leituras isoladas, uma vez que são justamente os aspectos semelhantes/diferentes que possibilitam significados peculiares da literatura ao ser analisada.

Nessa perspectiva, CROCE (1994, p. 61) explica que, "a literatura comparada busca as ideias ou temas literários e acompanham os acontecimentos, as alterações, as agregações, os desenvolvimentos e as influências reciprocas entre as diferentes literaturas".

Com efeito, investigar as temáticas literárias, bem como suas metamorfoses diacronicamente, constrói diálogos entre os diversos fatores sociais e as diferentes perspectivas de ver o mundo, que levaram autores a escreverem seus respectivos textos, sejam eles: contos, poemas, romances etc. isso acontece porque a literatura assume uma face universal, acompanhando o ser humano em suas realidades.

Ela percorre esse trajeto pelo uso das palavras e, além disso, coopera na produção de ramificações textuais, ou melhor, possibilita o uso da intertextualidade, fator este relevante para pensar a concatenação entre obras. Sendo assim, a literatura comparada fornece subsídios de análise, a fim de que o estudo seja realizado sistematicamente. Além de buscar, no cerne das obras, indícios de influências e intertextualidades.

Segundo CARVALHAL (2006, p. 54): "Trata-se de explorar criticamente os dois textos, ver como eles se misturam e, a partir daí, como, repetindo-o, o segundo texto "inventa" o primeiro. Dessa forma ele o redescobre, dando-lhe outros significados já não possíveis nele mesmos".

De fato, esses direcionamentos da LC mostram-se proveitosos à medida que o comparativista depara-se com seu corpus, confrontando-o com o intuito de observar os pormenores intrínsecos, já que não se trata de uma imitação de um autor sucessor, mas sim, de reinvenções estruturais, sociais e intencionais. Isto é, os sentidos são construídos tanto nas relações intertextuais, quanto nos novos traços, trazidos e reformulados pelos escritores, independente da sua época ou da sua nacionalidade. 
Ano 6, Vol. 6 (1), no 1. 2021, janeiro/julho de 2021.

\section{Chapeuzinho Vermelho}

É notório que a figura feminina nos contos de fadas estabelece uma relação de começo, meio e fim da própria trajetória de vida da mulher. Concretizada nas personagens chapeuzinho, mãe e vovó, tal pormenor sugere as tendências e responsabilidades sociais daquele tempo, cuja função da mulher era obedecer ou, simplesmente, ser mãe. Tanto é, ao desnudar o enredo, percebe-se que o caminho percorrido por Chapeuzinho vai além de um encontro familiar. Faz parte do seu caminho de vida, do seu destino, daquilo inerente ao sexo feminino e, por esse motivo, não podia desviar-se das suas obrigações femininas, ocasionando consequências fatídicas.

Em contrapartida à indisciplina e fragilidade da protagonista, existe a presença do caçador, este mostra-se como herói, versado e intrépido, isto é, opondo-se ao feminino. Nesse sentido, os fatores sociais emergem, de modo implícito, tanto na estrutura, quanto no enredo da história infantil.

De acordo com CANDIDO (2006, p.35):

Forças sociais condicionantes guiam o artista em grau maior ou menor. Em primeiro lugar, determinando a ocasião da obra ser produzida; em segundo, julgando da necessidade dela ser produzida; em terceiro, se vai ou não se tornar um bem

Nesse caso específico, os irmãos Grimm transmitem estes aspectos comportamentais da sociedade, justamente pelo caráter contributivo, que visavam ao selecionar e sistematizar a obra, em outras palavras, o anseio de advertir as crianças, pertinente para a época, concretizase à medida que os autores amalgamaram as possíveis situações perigosas no cotidiano aos elementos estruturais do conto de fadas.

\section{Chapeuzinho Amarelo}

A presença da intertextualidade é um traço marcante do conto/poema Chapeuzinho Amarelo, sendo ratificada, além do próprio título do texto, nos detalhes dos versos e no caráter 
Ano 6, Vol. 6 (1), no 1. 2021, janeiro/julho de 2021.

metalinguístico, uma vez que não somente faz alusões implícitas a Chapeuzinho Vermelho, mas constrói permanente diálogo com as idiossincrasias de sua precursora, bem como apontamentos indiretos aos autores primários e personagens importantes do conto de fadas.

\section{Chapeuzinho Amarelo}

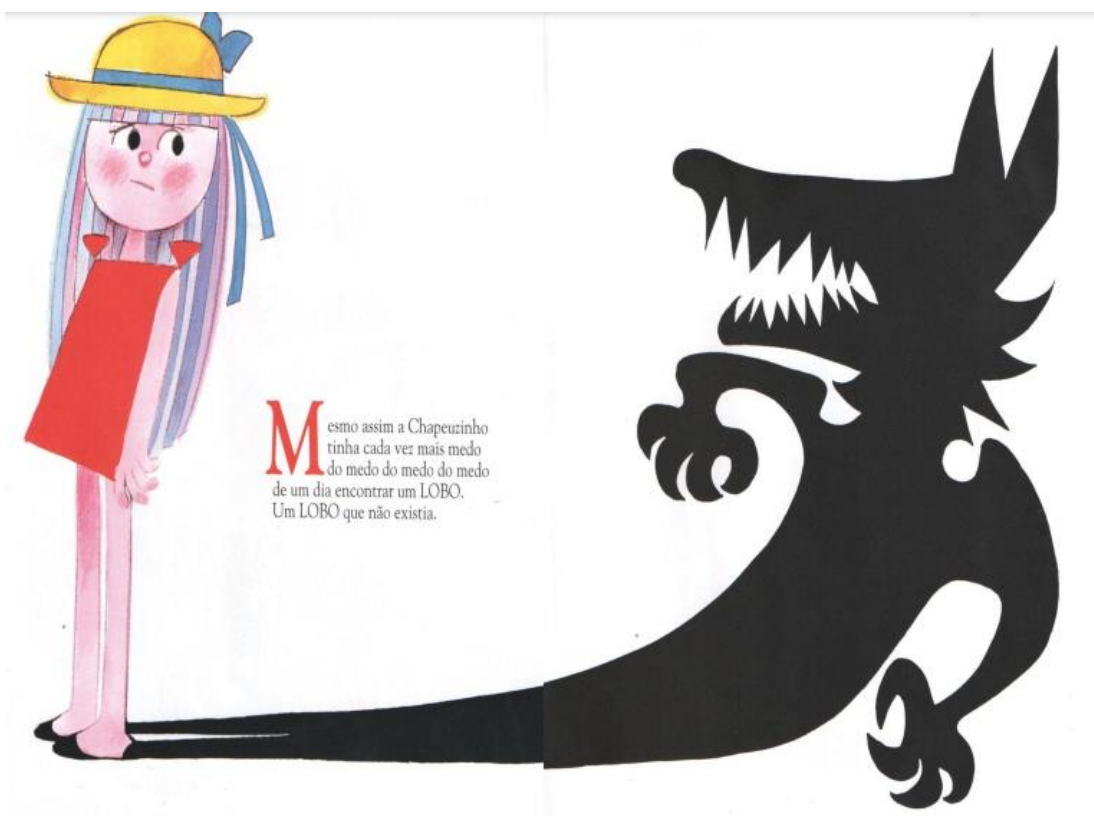

Fonte: Chico Buarque de Hollanda, 1979.

Desse modo, a mudança na forma narrativa renova o aspecto estrutural do primeiro texto enquanto conto de fadas, permitindo o uso de recursos estilísticos da poesia, por conseguinte, cria imagens inovadoras a partir do jogo com as palavras.

Ademais, Chapeuzinho Amarelo encontrava-se paralisada frente aos medos infantis, isto a privava de usufruir da sua existência, fazendo-a refém de si mesma. Embora seus estarrecimentos fossem exacerbados, ela consegue transpor essas barreiras a partir do encontro com o pior dos pesadelos (o Lobo).

Tal encontro provoca mudança na descrição da personagem, que depois de brincar com este ser perigoso o transforma em um dos alimentos prediletos das crianças. Dessa forma, a figura feminina sofre uma espécie de metamorfose, como acontece em Chapeuzinho Vermelho. 
Ou seja, a mulher não provoca problemas, pelo contrário, embora seja vítima de tantos medos, ela pode ultrapassá-los e, até mesmo, brincar com estes males.

Nesse contexto, vê-se o recurso bastante peculiar da poesia, conhecido como metáfora, nas palavras: Lobo/Bolo, no qual ratifica, além da transformação de vilão em alimento, a nova postura assumida pela Amarelo.

E Chapeuzinho Amarelo, de tanto pensar no LOBO, de tanto sonhar com LOBO, de tanto esperar o LOBO, um dia topou com ele que era assim: carão de LOBO, olhão de LOBO, jeitão de LOBO e principalmente um bocão tão grande que era capaz de comer duas avós, um caçador, rei, princesa, sete panelas de arroz e um chapéu de sobremesa. (HOLLANDA, 2011, p. 10).

Na tentativa de explicar este proceso de conotação metafórico, Candido diz:

A metáfora, que e um tipo especial de imagem. Ela se baseia na analogia, isto e, na possibilidade de estabelecer uma semelhança mental, e portanto uma relação subjetiva, entre objetos diferentes, abstraindo-se os elementos particulares para salientar o elemento geral, que assegura a correlação. (CANDIDO, 1996, p. 88).

Com efeito, a metáfora inaugura um novo patamar imagético no conto/poema, visto que, ao usar a semelhança entre as palavras Bolo/ Lobo, apesar de serem tão distintos, auxilia na modificação de papéis entre as personagens. Sendo assim, responsável por criar, dentro da intertextualidade, uma ligação intima entre a primeira versão do conto e a proposta de Chico Buarque.

\section{O vermelho e Chapeuzinho: o erotismo pensado por metáforas}

No conto Chapeuzinho Vermelho, vê-se por sentido de metáfora a construção sexual e o ciclo menstrual da puberdade, que está representado pelos artifícios contextuais que o enredo da obra apresenta. O próprio sentido da capa vermelha usada pela personagem já induz a possível relação de sexualidade, pois pelo conceito etimológico da palavra "CAPA", que significa algo que protege ou dá cobertura a uma determinada coisa, pode-se inferir que aquilo se refere (pensando pelo sentido das metáforas) na personificação da virgindade e da delicadeza 
da personagem, ao qual precisa de uma capa longa e vermelha (hímen) para protegê-la das ameaças que cercam o seu envolto.

O que para BETTELHEIM (2007, p. 240) faz todo o sentido, pois: "o vermelho é a cor que simboliza as emoções violentas, incluindo as sexuais". E a figura do Lobo representa, de certo modo, a figura do pênis, que ameaça a virgindade e a pureza de Chapeuzinho.

\section{Chapeuzinho Vermelho}

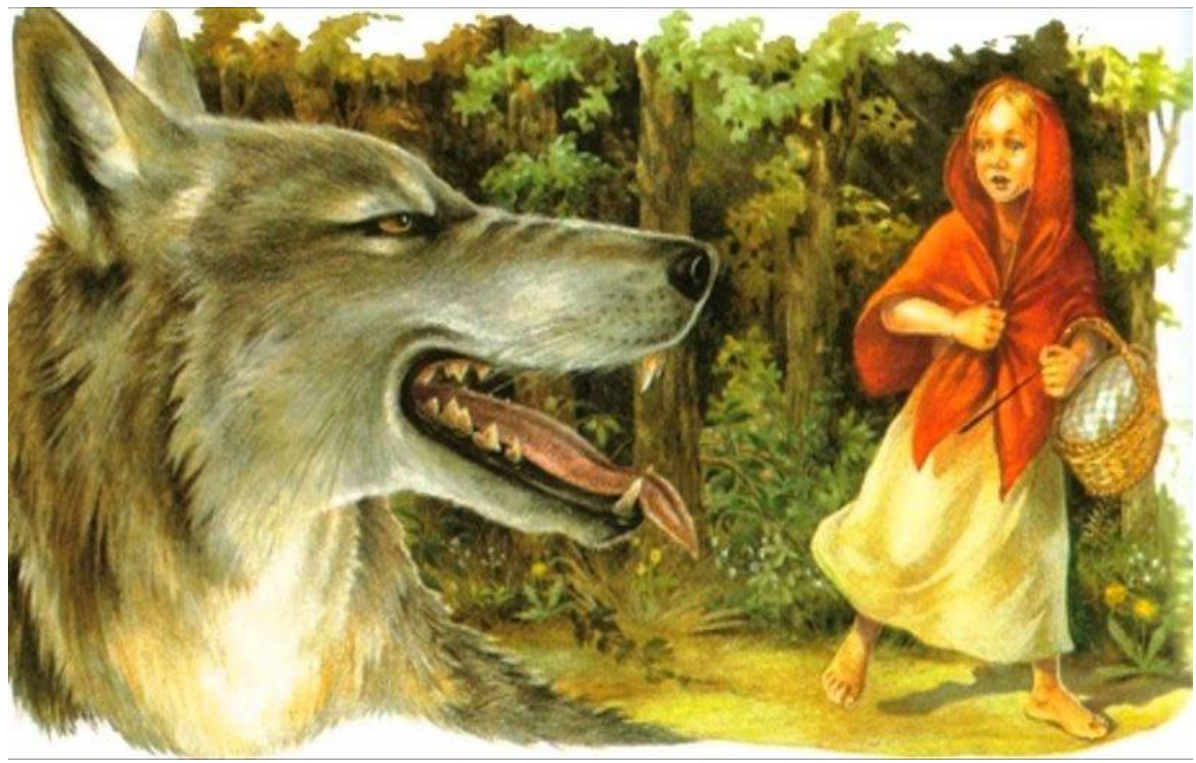

Fonte: Google.

No enredo do conto Chapeuzinho Vermelho, depreende-se pelo diálogo estabelecido entre os personagens no clímax que os elementos visuais dão margem para afirmar que o Lobo não está interessado em "comer" o que Chapeuzinho Vermelho carrega na cesta para a sua vovô, pois o seu direcionamento facial mira em torno da conjectura anatômica de Chapeuzinho. Além do mais, as suas afirmações quase sempre possuem um caráter ambíguo carregadas de sexualidade, portanto desconexa com a situação narrada, como se observa:

Olhando para aquela linda menina, o lobo pensou que ela devia ser macia e saborosa. Queria mesmo devorá-la num bocado só. Mas não teve coragem, temendo os cortadores de lenha que poderiam ouvir os gritos da vítima. Por isso, decidiu usar de astúcia. Chapeuzinho não conhecia o Lobo Mau; colocou um dedinho na boca e ficou a imaginar que espécie de animal seria aquele peludo. (GRIMM, 2015, p. 3). 
Pode-se evidenciar então, que isso foi uma tática utilizada pelo Lobo para conquistar a atenção de Chapeuzinho, ao qual pode-se confirmar pelas imagens que o conto gera aos leitores. O que para CANDIDO (1998, p. 12) é comum das obras literárias ficcionais: "como foi exposto antes, umas das funções essências da oração é a de projetar, como correlato, um contexto objectual que é transcendente ao mero conteúdo significativo, embora tenha nele seu fundamento ôntico".

Outro aspecto que é pertinente na discursão desse ponto diz respeito à própria morfologia do nome "LOBO", que, ao utilizar o recurso estilístico do Anagrama, extrai-se a palavra "BOLO", que ao pensar pelo caráter ambíguo e metafórico que o conto Chapeuzinho Vermelho produz, faz muito sentido para o embasamento deste trabalho, em virtude de que a questão do LOBO/BOLO está intrínseca com a relação da fome, que não somente se conceitua pela matéria vital para a nossa subsistência, e sim, pelo desejo carnal do sexo. Pois uma das várias faces das fomes é a necessidade por sexo. O que fica perceptível na construção do conto, pois há menções constantes à comida/comer/alimentar-se.

Já no texto de Chico Buarque, é o medo que centralizará o enredo da narrativa, se distanciando da premissa erótica manifesta no texto dos irmãos Grimm.

\section{O amarelo e Chapeuzinho: sobre a ótica da figura da mulher na sociedade}

A cor amarela personifica o atual cenário da sociedade, que ainda reprime, persegue e submete à mulher a condição de vulnerabilidade. Pode-se correlacionar até mesmo pelo ano de criação de Chapeuzinho Amarelo de Chico Buarque, 1979, que a figura taciturna e medrosa representada pela personagem é um reflexo autocrítico dos contextos que norteiam a mulher contemporânea, fazendo uso de uma ótica que traz à tona uma discussão delicada acerca de como se encontra a mulher dentro da sociedade nos dias atuais.

Proporcionando ao leitor uma reflexão intimista sobre essa realidade. Para se conseguir penetrar o cerne destas questões delicadas, é preciso um trabalho minucioso, pois como explica ZILBERMAN (2003, p. 191): “O processo é mais complexo quando se trata de uma literatura de denúncia social. Trata-se, neste caso, de incorporar à interioridade do livro infantil que os 
renegou por muito tempo. Por isso, sacode com as estruturas literárias, que precisam ser acomodadas à nova situação".

E Chico Buarque, ao ressignificar uma obra famosa dos contos de fadas, conseguiu incorporar e trazer essa discussão as entranhas do universo da Literatura Infantil. Mostrando e buscando apresentar uma nova roupagem da contemporaneidade por meio de uma personagem que é o espelho da representação da mulher do século XXI. Comprovando, desse modo, que essa problemática da repressão contra a mulher ainda e infelizmente, é um fator cultural enraizado em todos os cenários do plano existencial da sociedade.

Neste caso, a figura da mulher se traduz nesses anseios, dúvidas e inquietações pela qual Chapeuzinho Amarelo sente e passa. E outro lado dessa moeda se traduz em Chapeuzinho Vermelho. Onde ao se basear nos argumentos apresentados anteriormente, percebe-se que a figura da personagem é o estereótipo pelo qual a sociedade constrói acerca da mulher, pois ser mulher hoje ainda é viver em torno de rótulos e de valores predestinados por seu contexto social.

E Chapeuzinho Vermelho seria a personificação do que grande parte da sociedade ainda enxerga na mulher: uma visão machista e egoísta, que coloca a figura feminina em uma posição de submissão.

A capa, o chapéu, a preocupação da mãe, a figura grotesca do Lobo e a forma narrativa com que é descrita as personagens (sempre no diminutivo), faz com que se deduza e chegue a esta percepção: “Além da mãe, Chapeuzinho Vermelho não tinha outros parentes, a não ser uma avó bem velhinha, que nem conseguia mais sair de casa. Morava numa casinha, no interior da mata". (GRIMM, 2015, p. 1).

\section{Conclusão}

Os textos selecionados revelam como a perspectiva de ser mulher na infância dentro de um contexto literário foi alterada ao longo do tempo. Se antes a mulher era tida somente como causadora de problemas devido à sua falta de submissão, na contemporaneidade, apesar de tantos assombros, ela mostra-se superior aos desafios, ultrapassando os fantasmas do seu diaa-dia.

Não tem mais medo de chuva, nem foge de carrapato. Cai, levanta, se machuca, vai à praia, entra no mato, trepa em árvore, rouba fruta, depois joga 
Ano 6, Vol. 6 (1), no 1. 2021, janeiro/julho de 2021.

amarelinha com o primo da vizinha, com a filha do jornaleiro, com a sobrinha da madrinha e o neto do sapateiro. (HOLLANDA, 2011, p. 17).

Nessa perspectiva, a partir de ambas as obras, observa-se o uso dos recursos estruturais e estilísticos para interiorização da sociedade, a fim de construir o feminino das personagens com proficuidade. Isto é, os textos fazem com que a figura feminina participe do imaginário infantil, sem deixar de conter traços significativos da escrita destinada ao público pueril. Possibilita, então, a internalização desses contos de fadas, de modo que permaneçam reavivados na memória, além de revelar influências comportamentais da sociedade em séculos diferentes.

Além disso, tanto os Irmãos Grimm, preocupados em transmitir os contos da oralidade, quanto Chico Buarque, com sua capacidade poética de atualizar e modernizar a literatura, atentos às situações gerais que norteavam o contexto de suas épocas, tentaram reproduzir esses fatos por meio de suas obras, na intenção de promover um diálogo com a sociedade.

Para isso, obviamente, trouxeram o mundo imaginativo das crianças e os conhecimentos estéticos das suas respectivas épocas literárias. E por meio de duas narrativas, repletas de símbolos linguísticos e ambiguidades, buscaram e conseguiram aproximar o leitor para o universo de suas obras.

O que para Candido e Outros (1998, p. 24) é consequência do gênero narrativo, pois:

No poema isto é conseguido, antes de tudo, através da força expressiva da linguagem, que transforma a mera descrição em "vivência" duma personagem que erradamente se costuma confundir como o autor empírico. Mas, enquanto a poesia, na sua forma mais pura, se atém à vivência de um "estado", o gênero narrativo (e dramático) transforma o estado em processo, em distenção temporal.

Desse modo, as Chapeuzinhos partem do mesmo pressuposto: apresentar as nuances da mulher dentro da sociedade. E são, portanto, frutos da sua época: representando o Yin-yang das personas da mulher em seu decurso através dos tempos. 
Ano 6, Vol. 6 (1), n 1. 2021, janeiro/julho de 2021.

Referências bibliográficas

GRIMM, Irmãos. Chapeuzinho Vermelho. São Paulo: Rimeel, 2015.

HOLANDA, Chico Buarque de. Chapeuzinho Amarelo. 36p. Ilustrações de Ziraldo. José Olympio Editora, RJ, 2011.

CANDIDO, Antonio. Literatura e sociedade. $9^{a}$ ed. Rio de Janeiro: Ouro sobre azul, 2006.

CANDIDO, Antonio. O estudo Analítico do poema. $3^{\text {a }}$ ed. São Paulo: Humanitas Publicações / FFLCH/USP, 1996.

CARVALHAL, Tania Franco. Literatura comparada. 4a ed. São Paulo, Ática, 2006.

CROCE, Benetto. "A Literatura Comparada "In: COUTINHO \& CARVALHAL”. (Org.). Literatura comparada: textos fundadores. Rio de Janeiro: Rocco, 1994. p. 60-64.

GOTLIB, Nádia Battella. Teoria do conto. $11^{\text {a }}$ ed. São Paulo: Ática, 2006.

BETTELHEIM, Bruno. A psicanálise dos contos de fadas. Ed Paz e Terra S/A. São Paulo. 2007.

ZILBERMAN, Regina. Literatura Infantil na Escola. São Paulo: Global, 2003.

CANDIDO, Antonio. ROSENFELD, Anatol. PRADO, Décio de Almeida. GOMES, Paulo Emílio Sales. A Personagem de Ficção. 2a ed. São Paulo, Editora Perspectiva, 1998. 